\title{
Altered hippocampal gene expression and structure in transgenic mice overexpressing neuregulin 1 (Nrg1) type I
}

Inga H. Deakin', Beata R. Godlewska', Mary A. Walker ${ }^{1}$, Guo-Jen Huang², Markus H. Schwabb ${ }^{3,4}$, Klaus-Armin Nave ${ }^{3}$, Amanda J. Law ${ }^{1,5}$ and Paul J. Harrison (10 ${ }^{1,6}$

\begin{abstract}
Transgenic mice overexpressing the type I isoform of neuregulin 1 (Nrg1; NRG1) have alterations in hippocampal gamma oscillations and an age-emergent deficit in hippocampus-dependent spatial working memory. Here, we examined the molecular and morphological correlates of these findings. Microarrays showed over 100 hippocampal transcripts differentially expressed in $\mathrm{Nrg}^{\text {tg-type I }}$ mice, with enrichment of genes related to neuromodulation and, in older mice, of genes involved in inflammation and immunity. $\mathrm{Nrg}^{\text {tg-type I }}$ mice had an enlarged hippocampus with a widened dentate gyrus. The results show that Nrg1 type I impacts on hippocampal gene expression and structure in a multifaceted and partly age-related way, complementing the evidence implicating Nrg1 signaling in aspects of hippocampal function. The findings are also relevant to the possible role of NRG1 signaling in the pathophysiology of schizophrenia or other disorders affecting this brain region.
\end{abstract}

\section{Introduction}

Neuregulin 1 (Nrg1; NRG1) is a growth factor, signaling via $E r b b 3$ and Erbb4 receptor tyrosine kinases. Nrg1 plays diverse roles in the development, plasticity, and diseases of the nervous system ${ }^{1-5}$. Its pleiotropy arises, in part, from a family of structurally and functionally distinct isoforms (types I to VI), transcribed from different 5' exons $^{6}$. In humans, allelic variation can affect NRG1 isoform expression ${ }^{7-9}$, and polymorphisms in NRG1 may be a risk gene for schizophrenia ${ }^{10-12}$, although this has not been confirmed in genome-wide association studies ${ }^{13}$.

The type I isoform is affected in schizophrenia, with increased expression in hippocampus ${ }^{7}$ and prefrontal cortex ${ }^{14}$ compared with controls, and representing one of the abnormalities of NRG1-ErbB4 signaling observed in the disorder ${ }^{15-18}$. Reflecting the interest in the functional and pathological roles of NRG1 type I, a transgenic mouse selectively overexpressing this isoform $\left(\mathrm{Nrg} 1^{\text {tg-type I }}\right)$ was created $^{19}$, and shown to have alterations in myelination ${ }^{20}$ and some aspects of behavior ${ }^{21}$, including an ageemergent deficit in hippocampus-dependent spatial working memory ${ }^{22}$. Nrg $1^{\text {tg-type I }}$ mice also exhibit a reduced frequency of carbachol-induced hippocampal gamma oscillations ${ }^{22}$. These findings complement a broad body of evidence linking $\mathrm{Nrg} 1$ to hippocampal function and plasticity ${ }^{23-28}$. Differing phenotypic profiles are seen in other genetic mouse models of $\mathrm{Nrg1}$, highlighting the existence of isoform-specific properties ${ }^{29-34}$.

In the current study we examined two other aspects of the hippocampus in $\mathrm{Nrg}^{\mathrm{tg} \text {-type I }}$ mice: its transcriptome, and its structure, in comparison with wildtype (wt) littermates. Because of the age-dependent features of the hippocampal phenotype observed previously, the transcriptomic analysis was performed at two ages. 


\section{Materials and methods}

All experiments were conducted in accordance with the United Kingdom Animals (Scientific Procedures) Act, 1986, and had local ethical approval.

\section{Generation and genotyping of $\mathrm{Nrg} 1^{\text {tg-type I }}$ mice \\ The generation and genotyping of the $\mathrm{Nrg} 1^{\text {tg-type I }}$ mice has been described ${ }^{19}$. The mice overexpress Nrg1 type I ( $\beta 1$ a-isoform) under a Thy-1 promoter, with robust overexpression in multiple brain regions, including the hippocampus, with no alteration in $N r g 1$ types II or III $^{20,21}$. The experiments reported here were performed in F6-F9 generations of backcross of heterozygous $\mathrm{Nrg} 1^{\text {tg-type }}$ ${ }^{\mathrm{I}}$ males with wt C57BL/6 J females, comparing Nrg $1^{\text {tg-type I }}$ mice with their wt littermates.}

\section{Microarrays and quantitative real-time PCR (RT-qPCR)}

Two microarray experiments were performed, one in 'young adult' mice (2.5-4 months), the other in 'old' mice (14-15 months). Each comprised 24 animals, 6 of each genotype and sex.

\section{RNA extraction and preparation for microarrays}

Brains were frozen in isopentane cooled on dry ice. The left hemisphere was placed into RNAlater ${ }^{\circledR}$-ICE Frozen Tissue Transition Solution (Ambion) at $-20^{\circ} \mathrm{C}$ for $18 \mathrm{~h}$, after which the hippocampus was dissected and homogenized in Qiazol in a TissueLyser (Qiagen). Total RNA was extracted and purified with RNeasy lipid tissue Mini kits (Qiagen) according to manufacturer's protocol. In total, 300 ng RNA was used for amplification and labeling with Illumina ${ }^{\circledR}$ TotalPrep $^{\mathrm{Tm}}$ RNA Amplification Kit (Ambion). Complementary RNA (cRNA) quality was determined with an Agilent 2100 Bioanalyser (Agilent Technologies, Palo Alto, CA).

A total of $1.5 \mu \mathrm{g}$ cRNA from each brain was hybridized to an Illumina Mouse WG-6 v1.1 (young mice) or v2 (old mice) chip according to manufacturers' protocol and scanned with a BeadStation 500 machine.

\section{Microarray analysis}

Standard quality control measures were performed with the BeadStudio program (Illumina, CA), including subtracting the background from each array from the raw signal intensity of each probe type. The raw signal intensity data underwent variance stabilizing normalization, which is a generalized $\log _{2}$ transformation of the signal. A quantile standardization procedure was used to centralize the mean signal in the distribution (i.e., of all the probes) and to equalize the variance between mice. Further quality control was performed such as hierarchical clustering and box plots of normalized intensity (robust multichip average; RMA) values for each chip.
A linear model with an empirical Bayes $t$-statistic was fitted to the data to generate lists of significant effects of genotype, using the Limma program ${ }^{35}$. We corrected for multiple testing with the Benjamini-Hochberg false discovery rate to give an adjusted $p$ value ${ }^{36}$. The criteria for differential expression were an adjusted $p$ value $<0.05$ and an absolute (unlogged RMA) fold change in expression (FC) $>1.5$.

Differentially expressed probe lists were condensed into lists of differentially expressed transcripts, including known splice variants, identified with PubMed basic local alignment search tool (BLAST). Probes with no accession number were identified by nucleotide sequence with PubMed Nucleotide BLAST. Results from each array were compared with obtain lists of genes that were differentially expressed in NRG1 ${ }^{\text {tg-type I }}$ mice at both ages, or only at one of the two ages. These three lists of genes were used for further investigation with Ingenuity Pathways Analysis (IPA; Ingenuity Systems), which generated networks of up to 35 genes based on their known functional links ${ }^{37}$.

\section{$R T-q P C R$}

Hippocampal RNA was treated with $1 \mu \mathrm{l}(1$ unit) RQ1 RNase-free DNAse (Promega) and $0.6 \mu \mathrm{l}$ (24 units) RNasin ribonuclease inhibitor (Promega) at $37^{\circ} \mathrm{C}$ for $30 \mathrm{~min}$ and then heated to $72^{\circ} \mathrm{C}$ for $10 \mathrm{~min}$. DNAse-treated RNA was reverse-transcribed using $1 \mu \mathrm{l}$ (200 units) MMLV reverse transcriptase, Promega), 1xMMLV buffer, $0.8 \mu$ l of $10 \mathrm{mM}$ dNTPs, $0.6 \mu \mathrm{l}$ (24 units) RNasin, $0.6 \mu \mathrm{l}$ of $10 \mathrm{mM}$ oligoDTs. The reaction mix was incubated at $42^{\circ} \mathrm{C}$ for $1 \mathrm{~h}$ and then heated to $72{ }^{\circ} \mathrm{C}$ for $10 \mathrm{~min}$. The reversetranscribed RNA (complementary DNA; cDNA) was diluted with nuclease-free water and stored at $-80^{\circ} \mathrm{C}$.

TaqMan assays were ordered from Applied Biosystems (Npy, Mm00445771_m1; Gfap, Mm01253034_m1; Inhba, Mm00434339_m1; Cntfr, Mm00516697_m1; C1qa, Mm00432142_m1; Rbbp4, Mm00771401_g1). Bdnf was detected using pan-BDNF primers and a TaqMan probe (Forward, 5'-GGGTCACAG CGGCAGATAAA-3', Reverse 5'-GCCTTTGGATACCGGGACTT-3'; Probe, T CTGGCGGGACGGTCACAGTCCTA ${ }^{38}$. Bdnf v1specific probes $^{39}$ were: Forward, 5'-CACATTACCTTCC TGCATCTGTTG-3', reverse 5'-ACCATAGTAAGGAA AAGGATGGTCAT- $3^{\prime}$, probe AAGCCACAATGTTCC ACCAG. The PCR reaction mix included $15 \mathrm{ng}$ cDNA, 1xTaqMan Universal PCR Master Mix (Applied Biosystems) and the assay in a final volume (with nuclease-free water) of $15 \mu \mathrm{l}$ in 384-well plates. Nrg1 mRNA was quantified using a $\mathrm{SyBr}$ green assay, with the primers designed so that the PCR product would span the exon boundary between the type I-specific exon and the immunoglobulin-like domain, and checked in the BLAST database for binding specificity (Forward, 5'- 
AAGGGGAAGGGCAAGAAGAA-3', Reverse 5' TCTTTCAATCTGGGAGGCAAT-3'; Eurogentech). The reaction mix for $\mathrm{Nrg} 1$ type I was $1 \mathrm{xSyBr}$ Green Mix, $15 \mathrm{ng}$ cDNA, $200 \mathrm{nM}$ of each primer and nuclease-free water up to a final volume of $15 \mu \mathrm{l}$.

Standard curves of pooled cDNA from all samples were set up in triplicate with the starting amount of cDNA ranging from $100 \mathrm{ng}$ to $0.54 \mathrm{pg}(\mathrm{Nrg1}), 5 \mathrm{pg}(\mathrm{Npy}), 0.01 \mathrm{ng}$ (Gfap), or $0.39 \mathrm{ng}$ (Inhba, Cntfr, C1qa, Rbbp4). The $R^{2}$ of all standard curves was $>0.99$. All experimental samples fell within the standard curve. Samples were run in triplicate on the same plate as the standard curve. Notemplate controls and RT-negative controls were also run in triplicate to test for any contamination of the reaction mix or cDNA, respectively. Cycling conditions for all qRT-PCR reactions were $50^{\circ} \mathrm{C}$ for $2 \mathrm{~min}, 95^{\circ} \mathrm{C}$ for $10 \mathrm{~min}$ and then 40 repeats of $95^{\circ} \mathrm{C}$ for 15 seconds to denature and $60^{\circ} \mathrm{C}$ for $1 \mathrm{~min}$.

\section{Morphology and histology}

Snap-frozen brains from 10-month-old wt and $\mathrm{Nrg}{ }^{\mathrm{tg}-}$ type I mice were coronally cryosectioned at $20 \mu \mathrm{m}$ thickness. Hippocampal area was measured by point counting on multiple cresyl violet-stained sections throughout the dorsoventral extent, and hippocampal volume estimated using Cavalieri's theorem as described ${ }^{40}$. Whole brain volume was estimated in the same way. We also measured the cross-sectional area of subfields (dentate gyrus, CA3, CA1) by manual tracing using a Nikon Eclipse 3600 microscope coupled to an MCID Elite image analysis system (Interfocus, Haverhill, UK). Other sections were immunostained for parvalbumin (PV27, 1:100; Swant, Switzerland), detected with diaminobenzidine, by standard methods. All measurements were made blind to genotype.

\section{Results}

The hippocampal transcriptome of $\mathrm{Nrg}^{\text {tg-type I }}$ mice: agerelated effects on genes involved in myelination, neurotransmission, and immunity

Nrg1 impacts upon the expression of many individual genes $^{1,3}$. Here we used microarrays as an unbiased method to identify transcripts and networks altered in the hippocampus of $\mathrm{Nrg} 1^{\text {tg-type I }}$ mice. Adopting a stringent statistical approach, and with a 1.5 -fold change threshold, we identified over 100 differentially expressed genes, of which $\sim 80 \%$ were increased in $N r g 1^{\text {tg-type I }}$ mice compared with wt (Fig. 1a, and Supplementary Tables 1-3). Thirty-eight transcripts were altered in the same direction at both ages (Supplementary Table 1), 20 were differentially expressed only in the young adult (2.5-4 month) $N r g 1^{\text {tg-type I }}$ mice (Supplementary Table 2) and 54 only in old (14-15 month) Nrg1 ${ }^{\text {tg-type I }}$ mice (Supplementary Table 3). Eight transcripts were selected for qPCR validation, based on the microarray results as well as what was known about their functions and interactions with Nrg1 (Fig. 1b-d; and Table 1).

Genes upregulated at both ages in the NRG1 ${ }^{\text {tg-type I }}$ mice included neuropeptide $\mathrm{Y}(N p y)$, brain-derived neurotrophic factor $(B d n f)$, and glial fibrillary acidic protein (Gfap). Consistent with the Npy mRNA data, Npyimmunoreactive hippocampal interneurons were markedly more prominent in the $\mathrm{Nrg} 1^{\text {tg-type I }}$ mice (not shown). The $B d n f$ mRNA increase affected the V1 isoform selectively. IPA generated two networks with scores corresponding to significance values of $p=10^{-31}$ and $p=$ $10^{-25}$ (Supplementary Figs. 1 and 2). Network 1 included, as well as Npy and Bdnf, several transcripts involved in neurotransmission and implicated in schizophrenia, such as dopamine D1 and D4 receptors (Drd1 and Drd4).

Of the genes differentially expressed in young but not old $\mathrm{Nrg}^{\text {tg-type I }}$ mice, three were involved in myelination (myelin basic protein (Mbp), myelin oligodendrocyte glycoprotein (Mog), and myelin-associated oligodendrocytic basic protein). IPA generated a network that included $\operatorname{Mog}$ and $M b p\left(p=10^{-35}\right.$; Supplementary Fig. 3).

Genes overexpressed in old but not young $\mathrm{Nrg}^{\text {tg-type I }}$ mice (Supplementary Table 3) included many with immune and inflammatory functions, and IPA generated two highly significant networks $\left(p=10^{-37}\right.$ and $p=10^{-34}$; one is shown in Fig. 1e, the other in Supplementary Fig. 4). In particular, the network shown in Fig. 1e includes many upregulated HLA and major histocompatibility complex (MHC) genes (Supplementary Table 4).

\section{$\mathrm{Nrg} 1^{\text {tg-type I }}$ mice have altered hippocampal morphology}

As shown in Fig. 2a, the hippocampus was enlarged (by $\sim 25 \%)$ in $N r g 1^{\text {tg-type I }}$ mice, with brain volume unchanged. In terms of individual subfields, the only difference observed in $\mathrm{Nrg} 1^{\text {tg-type I }}$ mice was that the dentate gyrus granule cell layer was wider than in wt mice; this was primarily in the infra-pyramidal (external) blade rather than the supra-pyramidal (internal) blade (Fig. 2b, c). The density of PV + interneurons was unchanged in each subfield measured (Fig. 2d).

\section{Discussion}

Mice selectively overexpressing the type I isoform of $\mathrm{Nrg} 1$ show differences in hippocampal function and age-emergent deficits in hippocampus-dependent behavior ${ }^{22}$. Here, we report that these changes are accompanied by an altered profile of gene expression which differs between young adult (2.5-4 month) and old (14-15 month) $N r g 1^{\text {tg-type I }}$ mice, and by an increase in hippocampal volume.

\section{The hippocampal molecular and morphological profile of $\mathrm{Nrg} 1^{\text {tg-type }}$ ' mice}

$\mathrm{Nrg} 1^{\text {tg-type I }}$ mice exhibited differential expression of a number of genes (Fig. 1; Table 1; Supplementary Figures 


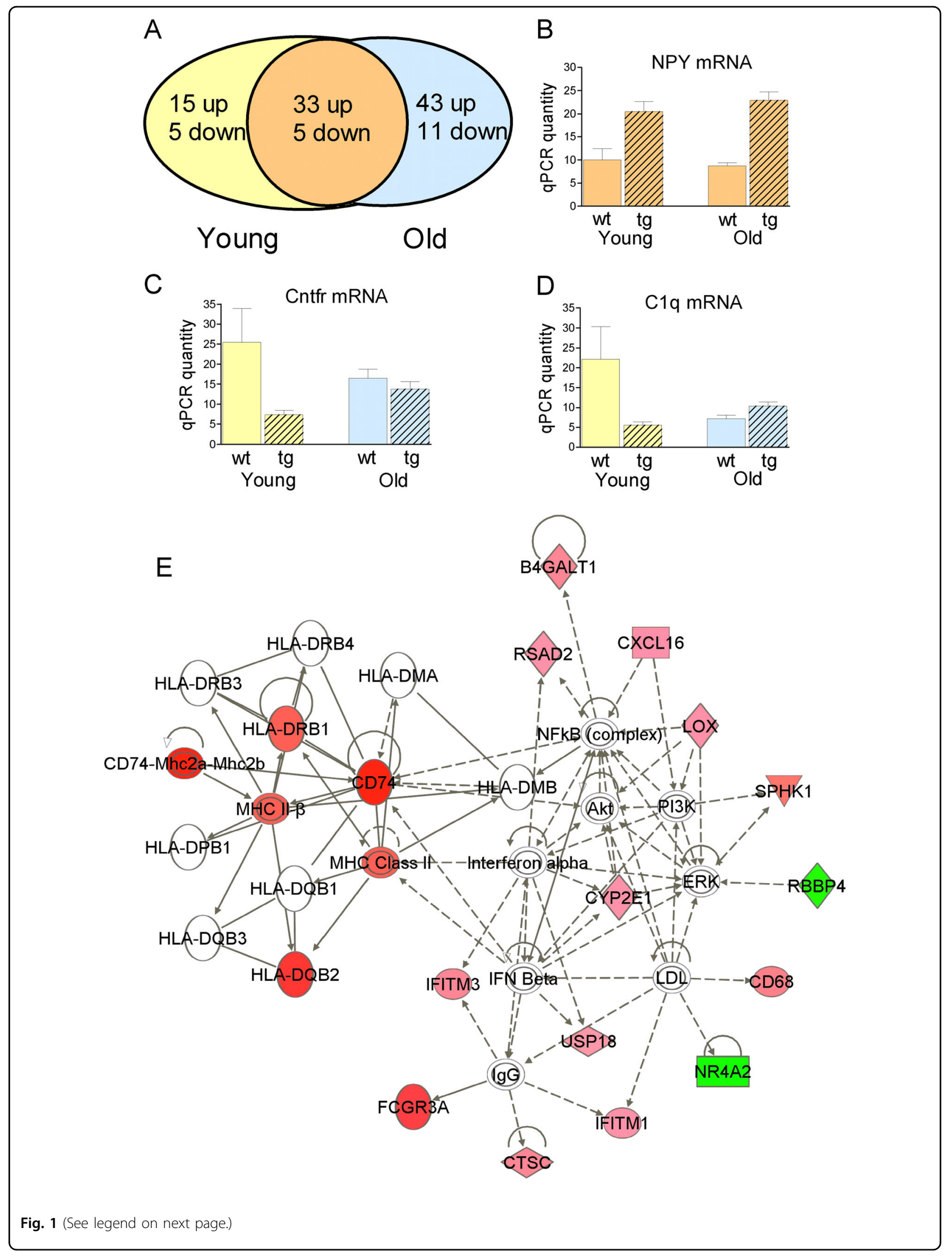


(see figure on previous page)

Fig. 1 Hippocampal gene expression in $\mathbf{N r g} 1^{\text {tg-type I }}$ mice. a Genes meeting the criteria described in text for differential expression in young (yellow) or old (blue) adult $\mathrm{Nrg}^{\text {tg-type I }}$ mice, or $\mathrm{Nrg}^{\text {tg-type I }}$ mice of both ages (orange). $\mathbf{b}$-d examples of RT-qPCR validation of transcripts from each group. b Npy mRNA, increased in Nrg ${ }^{\text {tg-type I }}$ mice of both ages; c Cntfr mRNA, decreased in young but not old adult Nrg $1^{\text {tg-type I }}$ mice; $\mathbf{d}$ C1q mRNA, increased in old but not young adult Nrg $7^{\text {tg-type I }}$ mice. Statistics for the data shown in panels $\mathbf{b}$-d are given in Table 1. e An IPA network of transcripts differentially expressed in old but not young adult Nrgltg-type I mice. The network comprises nodes (genes) and their biological relationships shown by interconnecting lines. Red nodes are transcripts with increased expression, and the green nodes are transcripts with lower expression, in the old $\mathrm{Nrg}^{\text {tg-type I }}$ mice, compared with their age-matched wt controls. Increasing color intensity indicates a greater fold change. White nodes show genes that are functionally related to the other differentially expressed genes in the network and added by IPA. Solid lines between nodes indicate a direct interaction between them and dashed lines indicate indirect relationships. A continuous line denotes "binding only"; pointed line, "acts upon" and blunt ended line, "inhibits". For gene symbols and names, see Supplementary Table 4. For additional IPA networks identified in one or both age groups of $\mathrm{Nrg}^{\text {tg-type I }}$ mice, see Supplementary Tables 1-3 and Supplementary Figures 1-4

Table 1 Quantitative RT-PCR validation of differentially expressed genes in $\mathrm{Nrg}^{\text {tg-type }}{ }^{1}$ mice

\begin{tabular}{|c|c|c|c|c|c|c|c|c|c|}
\hline \multirow[b]{3}{*}{ Accession } & \multirow[b]{3}{*}{ Gene } & \multicolumn{4}{|c|}{ Young adult (2.5-4 months) } & \multicolumn{4}{|c|}{ Old (4-15 months) } \\
\hline & & \multicolumn{2}{|c|}{ Microarray } & \multicolumn{2}{|c|}{ qRT-PCR } & \multicolumn{2}{|c|}{ Microarray } & \multicolumn{2}{|c|}{ qRT-PCR } \\
\hline & & FC & $p$ & FC & $p$ & FC & $p$ & $\mathrm{FC}$ & $p$ \\
\hline & NRG1 type I & 8.60 & 2.62E-19 & 801 & 0.001 & NA & NA & 466 & 0.001 \\
\hline NM_023456.2 & NPY & 2.22 & $1.01 \mathrm{E}-05$ & 2.0 & 0.005 & 2.46 & $9.93 \mathrm{E}-06$ & 2.6 & 0.001 \\
\hline NM_010277 & GFAP & 1.59 & $1.69 \mathrm{E}-03$ & NC & NC & 1.62 & $1.42 \mathrm{E}-02$ & 1.5 & 0.036 \\
\hline NM_007540.3 & BDNF v1 & 1.65 & 4.12E-04 & 3.5 & 0.001 & 2.76 & $8.00 \mathrm{E}-07$ & NC & NC \\
\hline NM_008380.1 & Inhba & 2.28 & 4.83E-06 & NC & NC & NC & NC & 2.7 & 0.001 \\
\hline NM_016673.1 & Cntfr & -1.86 & 5.66E-03 & -3.4 & 0.068 & $\mathrm{NC}$ & NC & NC & $\mathrm{NC}$ \\
\hline NM_007572 & C1qa & NC & NC & NC & NC & 1.60 & $6.14 \mathrm{E}-04$ & 1.4 & 0.032 \\
\hline NM_009030 & Rbbp4 & $\mathrm{NC}$ & NC & NC & $\mathrm{NC}$ & -1.89 & $6.14 \mathrm{E}-04$ & NC & $\mathrm{NC}$ \\
\hline
\end{tabular}

NA: probe not present on array. NC: no significant change. The statistical approach to the microarray data is described in text; $p$ values for qRT-PCR are from unpaired $t$ tests (two-tailed) comparing transgenic and wt mice of each age group

1-4; Supplementary Tables 1-3). Of the genes overexpressed in $\mathrm{Nrg}^{\text {tg-type I }}$ mice at both ages, several are noteworthy. In particular, five transcripts (Npy, Gfap, $B d n f$, $\operatorname{drd} 1$, and $D r d 4$ ) were part of the most significant gene network and all had been linked previously to $\mathrm{Nrg1}$. The fact they were upregulated in both age cohorts, which were studied separately and with different versions of the microarray chip, strengthens the robustness of the findings.

Npy is expressed by a subpopulation of hippocampal interneurons, bistratified and ivy cells, which impose a strong inhibitory influence on pyramidal cell dendrites $^{41,42}$. Its marked upregulation in the $\mathrm{Nrg}^{\text {tg-type I }}$ mice (Fig. 1b) is of interest for several reasons. First, it provides another hint that interneurons are affected and may contribute to the oscillatory and circuitry alterations that underlie the phenotype of the mice ${ }^{41-44}$. Second, $N p y$ is anti-epileptic ${ }^{45-47}$, and enhanced $N p y$ expression may help prevent the epileptiform predisposition of $N r g 1^{\text {tg-type }}$ ${ }^{I}$ mice ${ }^{22}$ progressing to overt seizure activity. Third, the Npy mRNA elevation may be related to the morphological finding of a widened dentate gyrus. Preliminary data show an increase of hilar cells immunoreactive for doublecortin, a marker of newly formed neurons, in the $\mathrm{Nrg} 1^{\text {tg-type I }}$ mice (I.H.D. and P.J.H., unpublished observations), suggesting that the enlarged dentate gyrus might reflect increased adult neurogenesis-a process stimulated by $N p y^{48-50}$, and influenced by $N r g 1^{51}$. Whether the persisting upregulation of Gfap mRNA in $N r g 1^{\text {tg-type I }}$ mice (Table 1) is also indicative of enhanced cell proliferationas many neural precursors express $G_{f a p^{2}}$-remains to be seen; it might also be a remnant of the developmental role of Nrg1-ErbB signaling in neuron-astrocyte differentiation $^{53,54}$. Bdnf is a regulator of hippocampal plasticity and function ${ }^{55}$, and its elevated expression may have many manifestations in the $\mathrm{Nrg}^{\mathrm{tg}-\text {-type I }}$ mice, including a contribution to their spatial working memory deficit ${ }^{22,56}$. Finally, the upregulation of Drd1 and Drd4 mRNAs complements evidence that hippocampal $\operatorname{Drd} 4$ mediates Nrg1-induced reversal of $\mathrm{LTP}^{24}$, and that Nrg1 application produces acute ${ }^{57}$ and sustained ${ }^{58}$ increases in dopamine release and dopamine neuron firing ${ }^{59}$. Another $\mathrm{Nrg}$ genetic mouse model also shows dopamine receptor alterations ${ }^{60}$. 

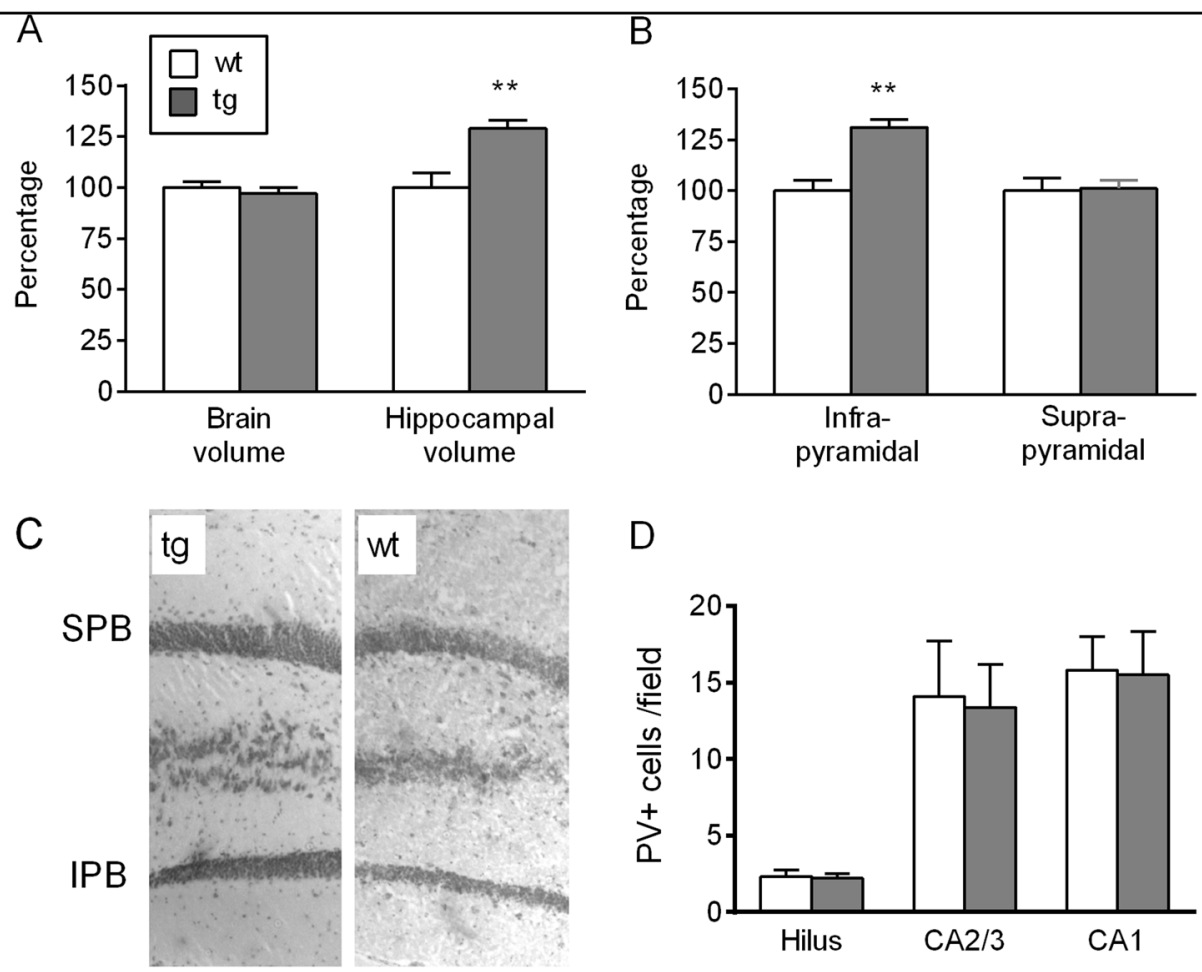

Fig. 2 Hippocampal morphology in $\mathbf{N r g} \mathbf{1}^{\text {tg-type I }}$ mice. a Hippocampal volume is increased in $\mathbf{N r g} 7^{\text {tg-type I }}$ mice $(n=10)$ compared with wt $(n=9$; two-tailed unpaired $t$ test, $t=3.249, \mathrm{df}=17, p=0.006$ ), but whole brain volume is unchanged. $\mathbf{b}$ The width of the dentate gyrus granule cell layer is

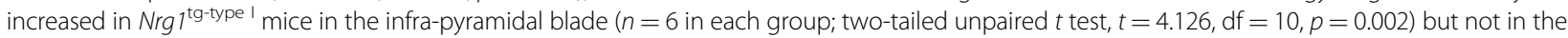
supra-pyramidal blade. $\mathbf{c}$ Illustration of the data in $\mathbf{b}$, showing the wider infra-pyramidal blade (IPB) in a Nrg $7^{\text {tg-type } 1}$ mouse compared with a wt mouse. The supra-pyramidal blade (SPB) is also shown, with CA3 in between. $\mathbf{d}$ The density of parvalbumin (PV)-immunoreactive cells did not differ in $\mathrm{Nrg}^{\text {tg-type I }}$ mice $(n=10)$ compared with wt $(n=12)$. Bars in $\mathbf{a}, \mathbf{b}$, and $\mathbf{d}$ show mean and standard deviation. All data in this Figure come from $10-$ month-old mice

The gene expression differences that occurred in the old but not young $N r g 1^{\text {tg-type I }}$ were striking, comprising many immune and inflammatory genes, such as HLA-DR, MHC class II CD74, and complement C1q. Similar changes have been reported in old vs. young wt rodents and in this respect there may be an 'accelerated aging' phenotype in $\operatorname{Nrg} 1^{\text {tg-type I }}$ mice ${ }^{61-64} \cdot C 1 q$, like other complement factors, is also involved in neuronal and synaptic function ${ }^{65-}$ ${ }^{67}$ and dysfunction ${ }^{68-70}$ and brain aging ${ }^{71}$. As such, the altered expression of the genes in the older $\mathrm{Nrg} 1^{\text {tg-type I }}$ mice may represent molecular correlates of, and might contribute to, their age-emergent memory impairment.

Fewer genes were differentially expressed in the young but not old $N r g 1^{\text {tg-type I }}$ mice, and they were primarily myelin-related. This is not unexpected, in that Nrg1 is a critical player in myelination ${ }^{72,73}$. Although the type I isoform has hitherto been implicated primarily in peripheral myelination ${ }^{19,74,75}$, these mice do show hypermyelination of small diameter axons in the central nervous system ${ }^{20}$. The upregulation of myelin-related transcripts in the $N r g 1^{\text {tg-type I }}$ mice may be a molecular indication that this process is also occurring in the hippocampus; any resulting hypermyelination may in turn contribute to the hippocampal volume increase. However, this remains speculative; indeed, more generally, the processes that link the morphological and molecular alterations reported here remain unknown.

The altered transcriptomic profile of the $\mathrm{Nrg} 1^{\text {tg-type I }}$ mice highlights an issue that pertains broadly to genetically modified animals: their phenotypes need not arise solely from the targeted gene(s) but also from the cascade of molecular changes which the manipulation induces. Moreover, these effects are not static but vary with age, and illustrate the value of going beyond the 3-6 month time-point at which characterization is often completed, even though capturing the temporal dynamic and longitudinal profile is demanding of resources and time.

\section{Implications for NRG1 in schizophrenia}

The evidence mentioned earlier showing Nrg1-dopamine interactions, and the increased D1 and D4 receptor expression seen here is notable, given that dopaminergic abnormalities are a final common pathway in schizophrenia pathophysiology ${ }^{76}$, and alterations in both 
receptors have been reported in the disorder ${ }^{77,78}$. The MHC complex is strongly implicated in schizophrenia ${ }^{79}$, in part through the complement $C 4$ gene $^{80}$, and several ${ }^{81-}$ ${ }^{84}$ though not all ${ }^{85}$ studies report elevated expression of many immune and inflammatory genes, including C1q, especially in older, chronically ill patients ${ }^{86}$, reminiscent of the gene expression changes being restricted to the old $N r g 1^{\text {tg-type I }}$ mice. There is also some evidence for direct links between NRG1, immune function, and schizophrenia $^{87-89}$.

However, there is less congruence when other findings are considered. Thus, in schizophrenia, in contrast to findings in the $N r g 1^{\text {tg-type I }}$ mice, hippocampal myelinrelated transcripts are decreased ${ }^{90}$, hippocampal volume is unchanged or reduced ${ }^{91}$, and there is a lower density of hippocampal PV + neurons ${ }^{92}$. Thus, although the phenotype of $\mathrm{Nrgl}^{\mathrm{tg}-\mathrm{g} y p e} \mathrm{I}$ mice may be seen as overlapping to an extent with that of schizophrenia, the differences are at least as striking as the similarities. One specific factor to consider is that the magnitude of overexpression in the $N r g 1^{\text {tg-type I }}$ mouse is far greater than the increased NRG1 type I expression reported in schizophrenia. More generally, these considerations draw attention to the need for cautious interpretation and extrapolation from any genetic mouse model to the human syndrome. Nevertheless, the results extend the evidence that Nrg1 type I is functional in the hippocampus, and hence may play a role in any disease in which its expression in this brain region is altered.

\section{Acknowledgements}

We thank P. Burnet, L. Chen, S. Eastwood, J. Flint K. Lamsa, H. Lockstone, W. Nissen, and J. Taylor for their contributions. I.H.D. was supported by a Wellcome Trust doctoral studentship. A.J.L. was a Medical Research Council (UK) Career Development Fellow. K.L. was a Wellcome Trust Career Development Fellow. Additional support from Stanley Medical Research Institute and Medical Research Council (UK) grants to P.J.H. M.H.S. holds a Heisenberg Fellowship from the Deutsche Forschungsgemeinschaft (DFG) and acknowleges funding by a DFG research grant (SCHW741/4-1).

\section{Author details}

${ }^{1}$ Department of Psychiatry, University of Oxford, Oxford, UK. ${ }^{2}$ Wellcome Trust Centre for Human Genetics, University of Oxford, Oxford, UK. ${ }^{3}$ Department of Neurogenetics, Max Planck Institute of Experimental Medicine, Goettingen, Germany. ${ }^{4}$ Center of Physiology, Hannover Medical School, Hannover, Germany. ${ }^{5}$ Department of Psychiatry, University of Colorado, Denver, USA. ${ }^{6}$ Oxford Health NHS Foundation Trust, Oxford, UK

\section{Conflict of interest}

The authors declare no conflicts of interest.

\section{Publisher's note}

Springer Nature remains neutral with regard to jurisdictional claims in published maps and institutional affiliations.

Supplementary Information accompanies this paper at (https://doi.org/ 10.1038/s41398-018-0288-2).

Received: 19 June 2018 Revised: 24 August 2018 Accepted: 26 September 2018
Published online: 22 October 2018

\section{References}

1. Corfas, G., Roy, K. \& Buxbaum, J. D. Neuregulin 1-erbB signaling and the molecular/cellular basis of schizophrenia. Nat. Neurosci. 7, 575-580 (2004).

2. Harrison, P. J. \& Law, A. J. Neuregulin 1 and schizophrenia: genetics, gene expression, and neurobiology. Biol. Psychiatry 60, 132-140 (2006).

3. Mei, L. \& Xiong, W. C. Neuregulin 1 in neural development, synaptic plasticity and schizophrenia. Nat. Rev. Neurosci. 9, 437-452 (2008).

4. Buonanno, A. The neuregulin signaling pathway and schizophrenia: from genes to synapses and neural circuits. Brain Res. Bull. 83, 122-131 (2010).

5. Mei, L. \& Nave, K. A. Neuregulin-ERBB signaling in the nervous system and neuropsychiatric diseases. Neuron 83, 27-49 (2014).

6. Steinthorsdottir, V. et al. Multiple novel transcription initiation sites for NRG1. Gene 342, 97-105 (2004).

7. Law, A. J. et al. Neuregulin 1 transcripts are differentially expressed in schizophrenia and regulated by $5^{\prime}$ SNPs associated with the disease. Proc. Natl. Acad. Sci. USA 103, 6747-6752 (2006).

8. Nicodemus, K. K. et al. A 5 'promoter region SNP in NRG1 is associated with schizophrenia risk and type III isoform expression. Mol. Psychiatry 14, 741-743 (2009).

9. Weickert, C. S., Tiwari, Y., Schofield, P. R., Mowry, B. J. \& Fullerton, J. M. Schizophrenia-associated HaplCE haplotype is associated with increased NRG1 type III expression and high nucleotide diversity. Transl. Psychiatry 2, e104 (2012).

10. Mostaid, M. S. et al. Neuregulin-1 and schizophrenia in the genome-wide association study era. Neurosci. Biobehav Rev. 68, 387-409 (2016).

11. Mostaid, M. S. et al. Elevated peripheral expression of neuregulin-1 (NRG1) mRNA isoforms in clozapine-treated schizophrenia patients. Transl. Psychiatry 7, 1280 (2017).

12. Jagannath, V., Gerstenberg, M., Correll, C. U., Walitza, S. \& Grünblatt, E. A systematic meta-analysis of the association of Neuregulin 1 (NRG1), D-amino acid oxidase (DAO), and DAO activator (DAOA)/G72 polymorphisms with schizophrenia. J. Neural Transm. Nienna) 125, 89-102 (2018).

13. Farrell, M. S. et al. Evaluating historical candidate genes for schizophrenia. Mol. Psychiatry 20, 555-562 (2015).

14. Hashimoto, R. et al. Expression analysis of neuregulin-1 in the dorsolateral prefrontal cortex in schizophrenia. Mol. Psychiatry 9, 299-307 (2004).

15. Hahn, C. G. et al. Altered neuregulin 1-erbB4 signaling contributes to NMDA receptor hypofunction in schizophrenia. Nat. Med. 12, 824-828 (2006).

16. Law, A. J., Kleinman, J. E., Weinberger, D. R. \& Weickert, C. S. Disease-associated intronic variants in the ErbB4 gene are related to altered ErbB4 splicevariant expression in the brain in schizophrenia. Hum. Mol. Genet. 16, 129-141 (2007).

17. Law, A. J. et al. Neuregulin 1-ErbB4-PI3K signaling in schizophrenia and phosphoinositide 3-kinase-p1108 inhibition as a potential therapeutic strategy. Proc. Natl. Acad. Sci. USA 109, 12165-12170 (2012).

18. Parlapani, E. et al. Gene expression of neuregulin-1 isoforms in different brain regions of elderly schizophrenia patients. World J. Biol. Psychiatry 11, 243-250 (2010).

19. Michailov, G. V. et al. Axonal neuregulin-1 regulates myelin sheath thickness Science 304, 700-703 (2004).

20. Brinkmann, B. G. et al. Neuregulin-1/ErbB signaling serves distinct functions in myelination of the peripheral and central nervous system. Neuron 59, 581-595 (2008).

21. Deakin, I. H. et al. Behavioural characterization of neuregulin 1 type I overexpressing transgenic mice. Neuroreport 20, 1523-1528 (2009).

22. Deakin, I. H. et al. Transgenic overexpression of the type I isoform of neuregulin 1 affects working memory and hippocampal oscillations but not longterm potentiation. Cereb. Cortex. 22, 1520-1529 (2012).

23. Kwon, O. B., Longart, M., Vullhorst, D., Hoffman, D. A. \& Buonanno, A. Neuregulin-1 reverses long-term potentiation at CA1 hippocampal synapses. J. Neurosci. 25, 9378-9383 (2005)

24. Kwon, O. B. et al. Neuregulin-1 regulates LTP at CA1 hippocampal synapses through activation of dopamine D4 receptors. Proc. Natl. Acad. Sci. USA 105, 15587-15592 (2008).

25. Neddens, J., Vullhorst, D., Paredes, D. \& Buonanno, A. Neuregulin links dopaminergic and glutamatergic neurotransmission to control hippocampal synaptic plasticity. Commun. Integr. Biol. 2, 261-264 (2009). 
26. Nason, M. W. Jr, Adhikari, A., Bozinoski, M., Gordon, J. A. \& Role, L. W. Disrupted activity in the hippocampal-accumbens circuit of type III neuregulin 1 mutant mice. Neuropsychopharmacology 36, 488-496 (2011).

27. Tamura, H., Kawata, M., Hamaguchi, S., Ishikawa, Y. \& Shiosaka, S. Processing of neuregulin-1 by neuropsin regulates GABAergic neuron to control neural plasticity of the mouse hippocampus. J. Neurosci. 32, 12657-12672 (2012).

28. Kawata, M., Morikawa, S., Shiosaka, S. \& Tamura, H. Ablation of neuropsinneuregulin 1 signaling imbalances ErbB4 inhibitory networks and disrupts hippocampal gamma oscillation. Transl. Psychiatry 7, e1052 (2017).

29. OTuathaigh, C. M. P. et al. Phenotypic characterization of spatial cognition and social behavior in mice with 'knockout' of the schizophrenia risk gene neuregulin 1. Neuroscience 147, 18-27 (2007).

30. Ehrlichman, R. S. et al. Neuregulin 1 transgenic mice display reduced mismatch negativity, contextual fear conditioning and social interactions. Brain Res. 1294, 116-127 (2009).

31. Duffy, L., Cappas, E., Lai, D., Boucher, A. A. \& Karl, T. Cognition in transmembrane domaine neuregulin 1 mutant mice. Neurosci 170, 800-807 (2010).

32. Yin, D. M. et al. Reversal of behavioral deficits and synaptic dysfunction in mice overexpressing neuregulin 1. Neuron 78, 644-657 (2013).

33. Luo, X., He, W., Hu, X. \& Yan, R. Reversible overexpression of bace1-cleaved neuregulin-1 N-terminal fragment induces schizophrenia-like phenotypes in mice. Biol. Psychiatry 76, 120-127 (2014)

34. Papaleo, F. et al. Behavioral, neurophysiological, and synaptic impairment in a transgenic neuregulin1 (NRG1-IV) murine schizophrenia model. J. Neurosci. 36 4859-4875 (2016).

35. Smyth, G. K. Limma: Linear models for microarray data. In: R. Gentleman, V. J. Carey, W. Huber, R. A. Irizarry, Dudoit S editors. Bioinformatics and Computational Biology Solutions Using R and Bioconductor. (pp. 397-420. Springer, New York, 2005).

36. Benjamini, Y. \& Hochberg, Y. Controlling the false discovery rate - a practical and powerful approach to multiple testing. J. Roy. Stat. Soc. B 57, 289-300 (1995).

37. Calvano, S. E. et al. A network-based analysis of systemic inflammation in humans. Nature 437, 1032-1037 (2005).

38. Burbach, G. J., Dehn, D., Del Turco, D. \& Deller, T. Quantification of layer-specific gene expression in the hippocampus: effective use of laser microdissection in combination with quantitative RT-PCR. J. Neurosci. Methods 131, 83-91 (2003).

39. Liu, Q. R. et al. Rodent BDNF genes, novel promoters, novel splice variants, and regulation by cocaine. Brain Res. 1067, 1-12 (2006).

40. Walker, M. A. et al. Estimated neuronal populations and volumes of the hippocampus and its subfields in schizophrenia. Am. J. Psychiatry 159, 821-828 (2002).

41. Klausberger, T. et al. Spike timing of dendrite-targeting bistratified cells during hippocampal network oscillations in vivo. Nat. Neurosci. 7, 41-47 (2004).

42. Fuentealba, P. et al. Ivy cells: a population of nitric-oxide-producing, slowspiking GABAergic neurons and their involvement in hippocampal network activity. Neuron 57, 917-929 (2008).

43. Tukker, J. J., Fuentealba, P., Hartwich, K., Somogyi, P. \& Klausberger, T. Cell typespecific tuning of hippocampal interneuron firing during gamma oscillations in vivo. J. Neurosci. 27, 8184-8189 (2007).

44. Gulyas, A. I. et al. Parvalbumin-containing fast-spiking basket cells generate the field potential oscillations induced by cholinergic receptor activation in the hippocampus. J. Neurosci. 30, 15134-15145 (2010).

45. Colmers, W. F., Lukowiak, K. \& Pittman, Q. J. Neuropeptide Y reduces orthodromically evoked population spike in rat hippocampal CA1 by a possibly presynaptic mechanism. Brain Res. 346, 404-408 (1985).

46. Sorensen, A. T. et al. Hippocampal NPY gene transfer attenuates seizures without affecting epilepsy-induced impairment of LTP. Exp. Neurol. 215, 328-333 (2009).

47. Gøtzsche, C. R. et al. Combined gene overexpression of neuropeptide $Y$ and its receptor Y5 in the hippocampus suppresses seizures. Neurobiol. Dis. 45, 288-296 (2012).

48. Gray, W. P. Neuropeptide Y signaling on hippocampal stem cells in health and disease. Mol. Cell Endocrinol. 288, 52-62 (2008).

49. Decressac, M. et al. Neuropeptide $Y$ stimulates proliferation, migration and differentiation of neural precursors from the subventricular zone in adult mice. Neurobiol. Dis. 34, 441-449 (2009)

50. Geloso, M. C., Corvino, V., Di Maria, V., Marchese, E. \& Michetti, F. Cellular targets for neuropeptide $Y$-mediated control of adult neurogenesis. Front. Cell Neurosci. 9, 85 (2015).
51. Ghashghaei, H. T. et al. The role of neuregulin-ErbB4 interactions on the proliferation and organization of cells in the subventricular zone. Proc. Natl. Acad. Sci. USA 103, 1930-1935 (2006).

52. Kriegstein, A. \& Alvarez-Buylla, A. The glial nature of embryonic and adult neural stem cells. Annu Rev. Neurosci. 32, 149-184 (2009).

53. Schmid, R. S. et al. Neuregulin 1-erbB2 signaling is required for the establishment of radial glia and their transformation into astrocytes in cerebral cortex. Proc. Natl. Acad. Sci. USA 100, 4251-4256 (2003).

54. Sardi, S. P., Murtie, J., Koirala, S., Patten, B. A. \& Corfas, G. Presenilin-dependent ErbB4 nuclear signaling regulates the timing of astrogenesis in the developing brain. Cell 127, 185-197 (2006).

55. Waterhouse, E. G. \& Xu, B. J. New insights into the role of brain-derived neurotrophic factor in synaptic plasticity. Mol. Cell Neurosci. 42, 81-89 (2009).

56. Cunha, C. et al. Brain-derived neurotrophic factor (BDNF) overexpression in the forebrain results in learning and memory impairments. Neurobiol. Dis. 33, 358-368 (2009).

57. Yurek, D. M., Zhang, L., Fletcher-Turner, A. \& Seroogy, K. B. Supranigral injection of neuregulin1-[beta] induces striatal dopamine overflow. Brain Res. 1028 116-119 (2004).

58. Kato, T. et al. Transient exposure of neonatal mice to neuregulin-1 results in hyperdopaminergic states in adulthood: implication in neurodevelopment hypothesis for schizophrenia. Mol. Psychiatry 16, 307-320 (2011).

59. Namba, H., Okubo, T. \& Nawa, H. Perinatal exposure to neuregulin-1 results in disinhibition of adult midbrain dopaminergic neurons: implication in schizophrenia modeling. Sci. Rep. 6, 22606 (2016).

60. Newell, K. A., Karl, T. \& Huang, X. F. A neuregulin 1 transmembrane domain mutation causes imbalanced glutamatergic and dopaminergic receptor expression in mice. Neuroscience 248, 670-680 (2013).

61. Verbitsky, M. et al. Altered hippocampal transcript profile accompanies an agerelated spatial memory deficit in mice. Learn Mem. 11, 253-260 (2004).

62. Frank, M. G. et al. mRNA upregulation of MHC II and pivotal pro-inflammatory genes in normal brain aging. Neurobiol. Aging 27, 717-722 (2006).

63. Kadish, l. et al. Hippocampal and cognitive aging across the lifespan: a bioenergetic shift precedes and increased cholesterol trafficking parallels memory impairment. J. Neurosci. 29, 1805-1816 (2009).

64. Pawlowski, T. L. et al. Hippocampal gene expression changes during agerelated cognitive decline. Brain Res. 1256, 101-110 (2009).

65. Stevens, B. et al. The classical complement cascade mediates CNS synapse elimination. Cell 131, 1164-1178 (2007).

66. Boulanger, L. M. Immune proteins in brain development and synaptic plasticity. Neuron 64, 93-109 (2009).

67. Bialas, A. R. \& Stevens, B. TGF-beta signaling regulates neuronal C1q expression and developmental synaptic refinement. Nat. Neurosci. 16, 1773-1782 (2013).

68. Di Filippo, M., Sarchielli, P., Picconi, B. \& Calabresi, P. Neuroinflammation and synaptic plasticity: theoretical basis for a novel, immune-centred, therapeutic approach to neurological disorders. Trends Pharmacol. Sci. 29, 402-412 (2008).

69. Chu, Y. X. et al. Enhanced synaptic connectivity and epilepsy in C1q knockout mice. Proc. Natl. Acad. Sci. USA 107, 7975-7980 (2010).

70. Michailidou, I. et al. Complement C1q-C3-associated synaptic changes in multiple sclerosis hippocampus. Ann. Neurol. 77, 1007-1026 (2015).

71. Ziv, Y. et al. Immune cells contribute to the maintenance of neurogenesis and spatial learning abilities in adulthood. Nat. Neurosci. 9, 268-275 (2006).

72. Chen, S. et al. Neuregulin 1-erbB signaling is necessary for normal myelination and sensory function. J. Neurosci. 26, 3079-3086 (2006).

73. Nave, K. A. \& Salzer, J. L. Axonal regulation of myelination by neuregulin 1. Curr. Opin. Neurobiol. 16, 492-500 (2006).

74. Taveggia, C. et al. Neuregulin-1 type III determines the ensheathment fate of axons. Neuron 47, 681-694 (2005).

75. Krishnan, A. Neuregulin-1 type I: a hidden power within Schwann cells for triggering peripheral nerve remyelination. Sci. Signal. 6, 270 (2013).

76. Howes, O. D. \& Kapur, S. The dopamine hypothesis of schizophrenia: version III--the final common pathway. Schizophr. Bull. 35, 549-562 (2009).

77. Harrison, P. J. Neurochemical alterations in schizophrenia affecting the putative receptor targets of atypical antipsychotics: Focus on dopamine $\left(D_{1}, D_{3}, D_{4}\right)$ and 5- $\mathrm{HT}_{2 \mathrm{~A}}$ receptors. Br. J. Psychiatry 174, 12-22 (1999).

78. Abi-Dargham, A. et al. Increased prefrontal cortical D-1 receptors in drug-naive patients with schizophrenia: a PET study with [C-11]NNC112. J. Psychopharmacol. 26, 794-805 (2012).

79. Schizophrenia Working Group of the Psychiatric Genomics Consortium.. Biological insights from 108 schizophrenia-associated genetic loci. Nature $\mathbf{5 1 1}$, 421-427 (2014). 
80. Sekar, A. et al. Schizophrenia risk from complex variation of complement component 4. Nature 530, 177-183 (2016).

81. Arion, D., Unger, T., Lewis, D. A., Levitt, P. \& Mirnics, K. Molecular evidence for increased expression of genes related to immune and chaperone function in the prefrontal cortex in schizophrenia. Biol. Psychiatry 62, 711-721 (2007).

82. Saetre, P. et al. Inflammation-related genes up-regulated in schizophrenia brains. BMC Psychiatry 7, 46 (2007).

83. Kim, S., Hwang, Y., Webster, M. J. \& Lee, D. Differential activation of immune/inflammatory response-related co-expression modules in the hippocampus across the major psychiatric disorders. Mol. Psychiatry 21 376-385 (2016).

84. Sanders, A. R. et al. Transcriptome sequencing study implicates immunerelated genes differentially expressed in schizophrenia: new data and a metaanalysis. Transl. Psychiatry 7, e1093 (2017).

85. Birnbaum, R. et al. Investigating the immunogenetic architecture of schizophrenia. Mol. Psychiatry 23, 1251-1260 (2017).

86. Narayan, S. et al. Molecular profiles of schizophrenia in the CNS at different stages of illness. Brain Res. 1239, 235-248 (2008)
87. Kanakry, C. G., Li, Z., Nakai, Y., Sei, Y. \& Weinberger, D. R. Neuregulin-1 regulates cell adhesion via an ErbB2/phosphoinositide-3-kinase/Akt-dependent pathway: potential implications for schizophrenia and cancer. PLOS ONE 2, e1369 (2007).

88. Marballi, K. et al. In vivo and in vitro genetic evidence of involvement of neuregulin 1 in immune system dysregulation. J. Mol. Med. 88, 1133-1141 (2010).

89. O'Leary, C. et al. Phenotypic effects of maternal immune activation and early postnatal milieu in mice mutant for the schizophrenia risk gene neuregulin-1. Neuroscience 277, 294-305 (2014).

90. Dracheva, S. et al. Myelin-associated mRNA and protein expression deficits in the anterior cingulate cortex and hippocampus in elderly schizophrenia patients. Neurobiol. Dis. 21, 531-540 (2006).

91. Harrison, P. J. The hippocampus in schizophrenia: a review of the neuropathological evidence and its pathophysiological implications. Psychopharmacology 174, 151-162 (2004).

92. Zhang, Z. J. \& Reynolds, G. P. A selective decrease in the relative density of parvalbumin-immunoreactive neurons in the hippocampus in schizophrenia. Schizophr. Res. 55, 1-10 (2002). 